\title{
Role of Disulfide Bonds for the Structure and Folding of Proguanylin ${ }^{\dagger}$
}

\author{
Thomas Lauber,*,‡ Axel Schulz, ${ }^{\S}$ Paul Rösch, ${ }^{\ddagger}$ and Ute C. Marx*,\$ \\ Lehrstuhl für Biopolymere, Universität Bayreuth, Universitätstrasse 30, 95447 Bayreuth, Germany, and \\ IPF PharmaCeuticals GmbH, Feodor-Lynen-Strasse 31, 30625 Hannover, Germany
}

Received February 13, 2004; Revised Manuscript Received April 30, 2004

\begin{abstract}
The intestinal peptide hormone guanylin circulates mainly as its corresponding prohormone of 94 amino acids and is the first identified endogenous ligand of intestinal guanylyl cyclase C. While the prohormone is biologically inactive, it is processed to the fully functional form with 15 amino acid residues corresponding to the $\mathrm{COOH}$ terminus of the precursor protein. In addition to this inactivation of the hormone region, the prosequence makes an essential contribution to the disulfide-coupled folding of the hormone. On the basis of the recently determined solution structure of proguanylin, explanations for these functions of the prosequence were found, indicating that interstrand contacts between the $\mathrm{NH}_{2}$-terminal $\beta$-hairpin of the prosequence and the $\mathrm{COOH}$-terminal hormone region are crucial for formation of the correct disulfide bonds of guanylin. To further investigate the role of individual disulfide bonds upon stabilization of the overall three-dimensional structure of proguanylin and to test the assumption of a direct effect of the prosequence on the structure of the hormone region, we studied the cysteine double mutant proteins proguanylin-C48S/C61S and proguanylin-C86S/C94S. Disulfide determination as well as CD and NMR spectroscopy of proguanylin-C48S/C61S reveals an essential function of the Cys48Cys61 disulfide bond for the stability of the hydrophobic core and thereby for the stability of the overall three-dimensional structure of proguanylin. Furthermore, sequence specific resonance assignment of the second disulfide deletion mutant, proguanylin-C86S/C94S, and comparison of the NMR spectra of this protein with those of the wild-type protein demonstrate that the rigid helical core structure of proguanylin is not affected by the mutation. Additionally, analysis of the interstrand contacts between the termini reveals a direct effect of the prosequence on the conformation of the hormone region. On the basis of these results, we propose a cooperative mechanism that leads to formation of the correct disulfide pattern of guanylin.
\end{abstract}

The peptide hormone guanylin is the first identified endogenous ligand of intestinal guanylyl cyclase C (GC-C) (1) and is part of a newly discovered entero-endocrine axis connecting intestine and kidney by regulating electrolyte and fluid secretion in the intestine (2) as well as kaliuresis and diuresis in the kidney $(3-6)$. In the intestine, binding of guanylin to GC-C leads to an increased level of intracellular cGMP that subsequently activates the cystic fibrosis transmembrane conductance regulator chloride channel, resulting in an increased level of secretion of $\mathrm{Cl}^{-}, \mathrm{HCO}_{3}{ }^{-}$, and water into the intestinal lumen, and simultaneously inhibits sodium absorption $(7,8)$. For GC-C binding and activation, formation of the correct $1-3 / 2-4$ disulfide bond pattern of guanylin is required $(1,9)$, allowing formation of two interconvertable topological stereoisomers (10), with only one of them (Aisomer) showing biological activity (11).

The main circulating form of guanylin is the corresponding 94-amino acid prohormone proguanylin, of which bioactive

\footnotetext{
† The study was funded by the "Deutsche Forschungsgemeinschaft" (DFG) (Project MA2317-1).

* To whom correspondence should be addressed. T.L.: phone, (+49) 921 552047; fax, (+49) 921 553544; e-mail, thomas.lauber@ gmx.de. U.C.M.: phone, (+49) 921 552048; fax, (+49) 921 553544; e-mail, ute.marx@uni-bayreuth.de.

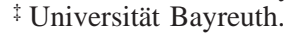

$\S$ IPF PharmaCeuticals GmbH.
}

guanylin corresponds to the $15 \mathrm{COOH}$-terminal amino acid residues (12; Figure 1a). The guanylin prohormone exhibits only negligible biological activity $(13,14)$ even though the sequence corresponding to mature guanylin (residues Pro80Cys94) is fixed in its bioactive A-isomer topology (15). On the basis of the solution structure of proguanylin published recently by our group, this issue can mainly be explained by numerous contacts between the hormone region and the $\mathrm{NH}_{2}$-terminal $\beta$-strand of the prosequence (15; Figure 1b). These interactions essentially stabilize the A-isomer topology of the hormone region and sterically prevent a B-form-like conformation. Additionally, they shield part of the hormone surface that is thus not accessible for interactions with GC$\mathrm{C}$, explaining the significantly decreased receptor binding affinity (13) of the guanylin prohormone (15).

The highly homologous peptide hormones guanylin and uroguanylin both require their respective prosequence for the disulfide-coupled folding. For this function of the prosequence, the $\mathrm{NH}_{2}$-terminal residues are particularly important as indicated by the fact that all $\mathrm{NH}_{2}$-terminally truncated variants of both prohormones that were examined exhibit non-native disulfide connectivities in the hormone region (14, 16, 17). As known from the three-dimensional proguanylin structure, all truncations affect the central strand of the triplestranded $\beta$-sheet and thus the interactions between the termini, leading to the suggestion that the interstrand 

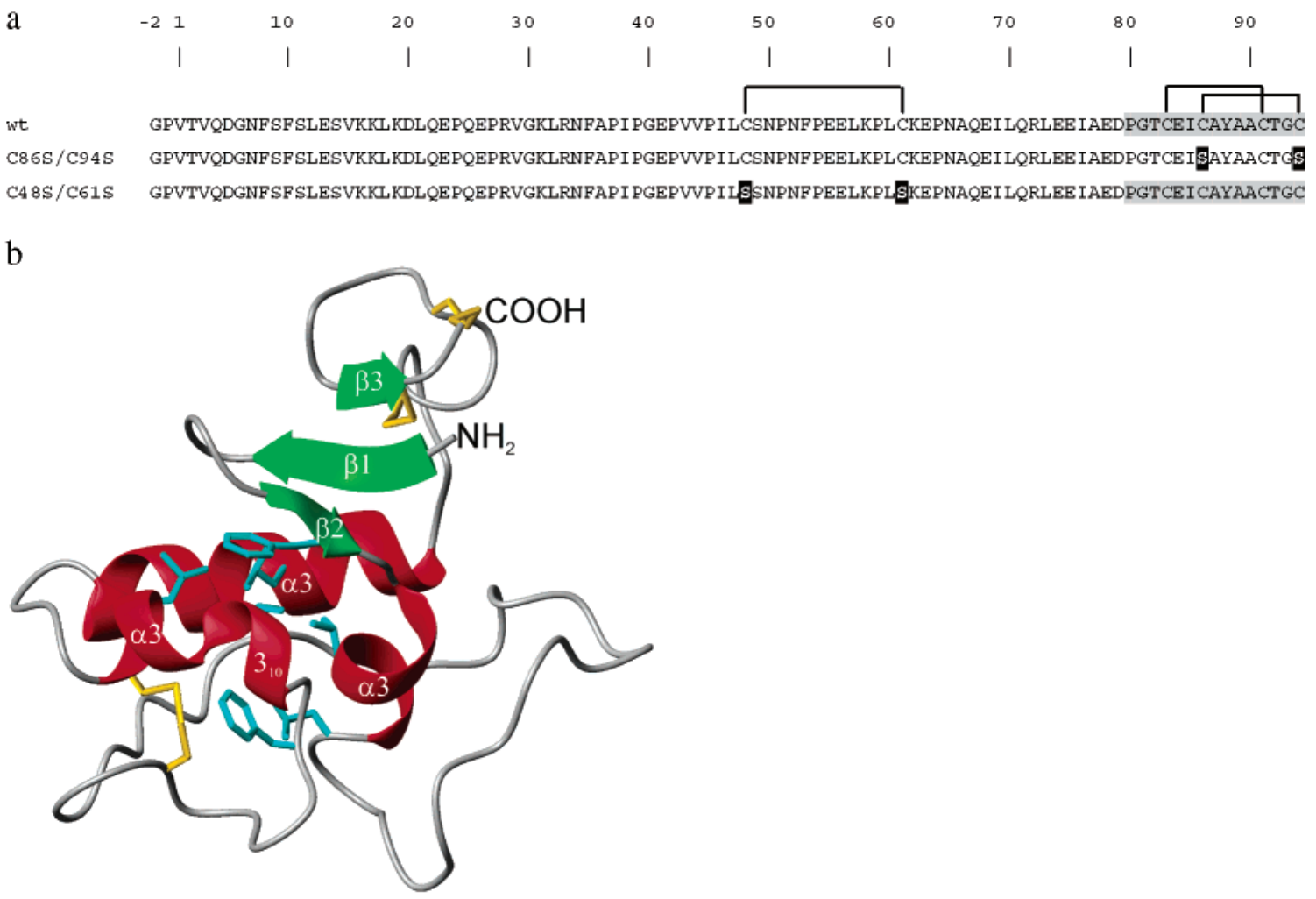

FIGURE 1: (a) Amino acid sequences and disulfide pattern of recombinant wild-type proguanylin (wt), proguanylin-C86S/C94S (C86S/ C94S), and proguanylin-C48S/C61S (C48S/C61S). Cysteine residues substituted with serine are highlighted in black, and the sequence corresponding to mature 15 -amino acid residue guanylin is highlighted in gray. Residues at sequence positions -1 and -2 result from cleavage of the thioredoxin fusion protein during production of the recombinant proteins (see Materials and Methods). (b) Schematic representation of the wild-type proguanylin topology (15). Helices and sheet structures are in red and green, respectively. The side chains of the hydrophobic core residues (i.e., Phe10, Val15, Leu18, Phe53, Leu57, Leu60, and Leu73) are in cyan, and disulfide bonds between residues 48 and 61, 83 and 91, and 86 and 94 are in yellow. Panel b was generated with MOLMOL (41).

interactions responsible for shielding the hormone region are also essential for correct disulfide bond formation (15).

To further investigate if the structure of the prosequence is indeed essential for and involved in the correct assembly of the three-dimensional structure of proguanylin, we recombinantly expressed two disulfide mutant proteins (Figure 1a) in addition to the wild-type protein (18). The substitutions of cysteine residues 86 and 94 with serine were expected to enhance the flexibility of the hormone region and thereby disturb the stabilizing interactions between the termini. Also, the formerly unknown function of the third disulfide bond of proguanylin (Cys48-Cys61) was analyzed with respect to stabilization of the three-dimensional structure, as well as its contribution to the oxidative folding of this precursor protein.

\section{MATERIALS AND METHODS}

Construction of Expression Vectors. For construction of a pET-32a derivative for production of recombinant proguanylin-C48S/C61S, the vector pET-32a-pres-proguanylin (18) was used as a template for site-directed mutagenesis by overlap extension (19). The forward primer for amplification of the $5^{\prime}$ end of the proguanylin gene (primer a) introduces a $B g l I I$ site and a sequence encoding a PreScission proteinase cleavage site in this region (primer a, GGA GGA A GAT CTG GGT GAC GAC GAC GAC GAC CTG GAA GTT CTG TTC CAG GGG CCC GTC). The reverse primer (primer b) contains the C48S mutation (GGA GGA GAG TTC TTC TGG AAA GTT CGG GTT GCT GCT GAG
GAT GGG AAC CAC). For amplification of the 3' end of the gene, the forward primer (primer c, GGA GGA AAC CCG AAC TTT CCA GAA GAA CTC AG CCT CTC AGC AAG GAG CCC AAT GCC) contains the C61S mutation, and the reverse primer (primer d) introduces an $\mathrm{NcoI}$ site at its $5^{\prime}$ end (GGA GGA CCA TGG TTA GCA TCC GGT ACA GGC AGC GTA GG). Following annealing of complementary regions of the two $\mathrm{PCR}^{1}$ fragments corresponding to parts of primers $\mathrm{b}$ and $\mathrm{c}$, and synthesis of complementary strands, the mutated DNA was amplified using primers a and $\mathrm{d}$ as forward and reverse primers, respectively. This PCR fragment was inserted into T7 RNA polymerase-based expression vector pET-32a (Novagen, Madison, WI).

For construction of a pET-32a derivative for production of recombinant proguanylin-C86S/C94S, the QuickChange Multi Site-directed Mutagenesis Kit (Stratagene, La Jolla, CA) was used according to the manufacturer's instructions with a single phosphorylated mutagenesis primer (CCA TGG

\footnotetext{
${ }^{1}$ Abbreviations: CD, circular dichroism; DSS, 2,2-dimethyl-2silapentane-5-sulfonic acid; ESI-MS, electrospray ionization mass spectrometry; HNHA, three-dimensional heteronuclear $\left({ }^{1} \mathrm{H}-{ }^{15} \mathrm{~N}-{ }^{1} \mathrm{H}\right)$ shift correlation double-resonance NMR experiment; HPLC, highperformance liquid chromatography; HOAc, acetic acid; HSQC, heteronuclear single-quantum coherence NMR experiment; NOE, nuclear Overhauser effect, also used for NOESY cross-peak; NOESY, NOE spectroscopy; PAGE, polyacrylamide gel electrophoresis; PCR, polymerase chain reaction; NMR, nuclear magnetic resonance; SDS, sodium dodecyl sulfate; TOCSY, total correlation spectroscopy; Trx, E. coli thioredoxin A.
} 
TTA GCT TCC GGT ACA GGC AGC GTA GGC GCT GAT TTC ACA TG) and the previously published vector pET-32a-pres-proguanylin as a template (18).

The resulting vectors pET-32a-pres-proguanylin-C48S/ C61S and pET-32a-pres-proguanylin-C86S/C94S are able to produce the proteins proguanylin-C48S/C61S and proguanylin-C86S/C94S with an $\mathrm{NH}_{2}$-terminal Escherichia coli thioredoxin fusion (Trx tag, Novagen). Trx tag and the proguanylin mutant proteins are connected by a 46 -amino acid linker containing six histidine residues and a PreScission proteinase cleavage site (LEVLFQلGP).

Sample Preparation. Recombinant proguanylin, proguanylin-C48S/C61S, and proguanylin-C86S/C94S were expressed as thioredoxin fusion proteins in E. coli AD494(DE3) cells (Novagen) and purified as described previously (18). For uniform $(>95 \%){ }^{15} \mathrm{~N}$ labeling, the recombinant proteins were isolated and purified from $E$. coli cultures grown in M9 minimal medium enriched with ${ }^{15} \mathrm{NH}_{4} \mathrm{Cl}$ using the same purification protocol. As the expression strain lacks the ability to synthesize leucine, ${ }^{15} \mathrm{~N}$-labeled leucine was added to the medium according to the manufacturer's instructions (Novagen).

Analytical HPLC and Mass Spectrometry. Analytical HPLC was carried out on a Jupiter C18 column (Phenomenex, $5 \mu \mathrm{m}, 300 \AA, 1.5 \mathrm{~mm} \times 250 \mathrm{~mm}$; solvent $\mathrm{A}, 0.1 \%$ TFA; solvent $\mathrm{B}, 0.1 \%$ TFA in a $4: 1 \mathrm{MeCN} / \mathrm{H}_{2} \mathrm{O}$ mixture; gradient, from 10 to $70 \%$ solvent $\mathrm{B}$ over the course of 60 min; flow rate of $0.2 \mathrm{~mL} / \mathrm{min}$; UV detection at $215 \mathrm{~nm}$ ) at a column temperature of $11{ }^{\circ} \mathrm{C}$. Electrospray mass spectrometrical analysis (ESI-MS) was carried out on either a Sciex API III (Perkin-Elmer) or a LCT time-of-flight mass spectrometer (Micromass Ltd., Wythenshawe, U.K.).

Acetic Acid Cleavage of Proguanylin. Samples of recombinant proguanylin and proguanylin-C48S/C61S $(50 \mu \mathrm{g})$ were incubated in $50 \mu \mathrm{L}$ of $1 \mathrm{M} \mathrm{HOAc}$ at $95{ }^{\circ} \mathrm{C}$ for $60 \mathrm{~min}$. The reactions were stopped by freezing the mixtures with liquid nitrogen, and the samples were lyophilized. The remaining material of each sample was dissolved in $50 \mu \mathrm{L}$ of $\mathrm{H}_{2} \mathrm{O}$ and subjected to ESI-MS and HPLC.

Reduction and Oxidative Folding of Proguanylin. Reduction of recombinant wild-type proguanylin was carried out for $3 \mathrm{~h}$ at $60{ }^{\circ} \mathrm{C}$ and at a protein concentration of $0.3 \mathrm{mg} /$ $\mathrm{mL}$ in $100 \mathrm{mM} \mathrm{NH}_{4} \mathrm{HCO}_{3}$ and $100 \mathrm{mM} \mathrm{DTT} \mathrm{(pH} \mathrm{8.3).} \mathrm{The}$ reduced protein was purified by RP-HPLC on a preparative C18 column (Macherey \& Nagel; solvent A, 0.1\% TFA; solvent $\mathrm{B}, 0.1 \%$ TFA in a $4: 1 \mathrm{MeCN} / \mathrm{H}_{2} \mathrm{O}$ mixture; gradient, from 20 to $80 \%$ solvent B over the course of $40 \mathrm{~min}$; flow rate of $10 \mathrm{~mL} / \mathrm{min}$; UV detection at 220 and $280 \mathrm{~nm}$ ) and analyzed by ESI-MS.

Oxidative folding of the reduced protein was carried out at a protein concentration of $0.05 \mathrm{mg} / \mathrm{mL}$ in refolding buffer [100 mM NH $\mathrm{NHCO}_{3}, 2 \mathrm{mM}$ EDTA, and $1.0 \mathrm{mM}$ cysteine/ $0.05 \mathrm{mM}$ cystine $\left(\mathrm{pH} \mathrm{8.3)]} \mathrm{at} 4{ }^{\circ} \mathrm{C}\right.$ for $18 \mathrm{~h}(14)$.

For analysis of disulfide intermediates, the folding reaction was quenched after 10, 30, 60, 90, 120, and $180 \mathrm{~min}$ and 18 $\mathrm{h}$ by acidification to $\mathrm{pH} \approx 2$ [addition of TFA to a final concentration of $4 \%(\mathrm{v} / \mathrm{v})]$, and samples were subjected to acetic acid cleavage. The cleavage products were analyzed by SDS-PAGE (NuPAGE, Invitrogen Corp., Carlsbad, CA) under reducing and oxidizing buffer conditions.

CD Spectroscopy. Far-UV CD spectra were recorded on a Jasco J-810 spectropolarimeter (Jasco Inc., Gross-Umstadt,
Germany) at room temperature (i.e., $20{ }^{\circ} \mathrm{C}$ ) with $9.5 \mu \mathrm{M}$ recombinant wild-type proguanylin, $6.2 \mu \mathrm{M}$ proguanylin$\mathrm{C} 48 \mathrm{~S} / \mathrm{C} 61 \mathrm{~S}$, and $8.6 \mu \mathrm{M}$ proguanylin-C86S/C94S each in a $0.1 \mathrm{~cm}$ cell. The buffer conditions applied to all protein samples were $10 \mathrm{mM}$ potassium phosphate and $\mathrm{pH} 6.0$. Spectra were measured from 260 to $185 \mathrm{~nm}$ at $20 \mathrm{~nm} / \mathrm{min}$. The particular reference samples contained buffer without protein. Spectra were measured six times and averaged for sample and reference.

NMR Spectroscopy. All NMR experiments were performed at $293 \mathrm{~K}$ on either a Bruker Avance 400 or a DRX600 NMR spectrometer equipped with inverse ${ }^{1} \mathrm{H} /{ }^{13} \mathrm{C} /{ }^{15} \mathrm{~N}\left({ }^{31} \mathrm{P}\right)$ triple or quadruple resonance probes with pulsed field gradient capabilities. For resonance assignment of proguanylin-C86S/ C94S, the following heteronuclear two-dimensional and three-dimensional NMR experiments were performed on a uniformly ${ }^{15} \mathrm{~N}$-labeled sample at a final concentration of 1 $\mathrm{mM}$ in $50 \mathrm{mM}$ sodium phosphate $\left(10 \% \mathrm{D}_{2} \mathrm{O}, \mathrm{v} / \mathrm{v}\right)$ at $\mathrm{pH}$ 6.0: ${ }^{15} \mathrm{~N}$ HSQC $(20)$, HNHA $(21,22),{ }^{15} \mathrm{~N}$ TOCSY-HSQC (23) (80 ms mixing time), and ${ }^{15} \mathrm{~N}$ NOESY-HSQC (24) (120 ms mixing time). The $\mathrm{H}_{2} \mathrm{O}$ resonance was suppressed with a binomial 3-9-19 WATERGATE sequence (25) with water flip-back (26), except for the ${ }^{15} \mathrm{~N}$ TOCSY-HSQC spectrum that was recorded with gradient coherence selection for water suppression (27). Quadrature detection in the indirectly detected dimensions was achieved with the States-TPPI method $(28,29)$ or with the echo-antiecho method $(30)$ if coherence selection with gradients was employed $(27,31)$. For proton TOCSY mixing, the DIPSI2rc sequence was applied (32), and for heteronuclear decoupling during acquisition, the GARP pulse sequence (33) was applied. Multidimensional NMR data were extrapolated to up to twice the acquisition time by linear prediction in the ${ }^{15} \mathrm{~N}$ indirect dimension, apodized by multiplication with squared sine bells shifted by $60-90^{\circ}$, and extended to at least twice the length by zero-filling in all dimensions prior to Fourier transformation. The baseline in the direct dimension was corrected using a model-free algorithm (34). The NMR data were processed using in-house written software (35) and analyzed with the program packages NMRView (36) and NDEE (SpinUp Inc., Dortmund, Germany). ${ }^{1} \mathrm{H}$ chemical shifts were referenced with respect to external DSS in $\mathrm{D}_{2} \mathrm{O}$, and ${ }^{15} \mathrm{~N}$ chemical shifts were referenced indirectly (37).

\section{RESULTS AND DISCUSSION}

Spectroscopic Analysis of Proguanylin-C86S/C94S and Comparison with Wild-Type Proguanylin. The crucial function of the guanylin prosequence in disulfide-coupled folding is thought to be mediated by interstrand contacts between the $\mathrm{NH}_{2}$-terminal $\beta$-hairpin and the $\mathrm{COOH}$-terminal hormone region of proguanylin that stabilize a guanylin A-isomerlike topology (Figure 1b) (15). Explicit evidence for a direct effect of the fold of the prosequence on the structure of the hormone region, however, has not been reported yet. To gain further insight into the requirements necessary for correct formation of the structure and disulfides of guanylin in its precursor protein, we intended to enhance the conformational freedom of the hormone region to thereby destabilize the interactions between the termini. We therefore substituted cysteine residues 86 and 94 with serine, and the resulting protein proguanylin-C86S/C94S was analyzed by far-UV CD as well as NMR spectroscopy. 


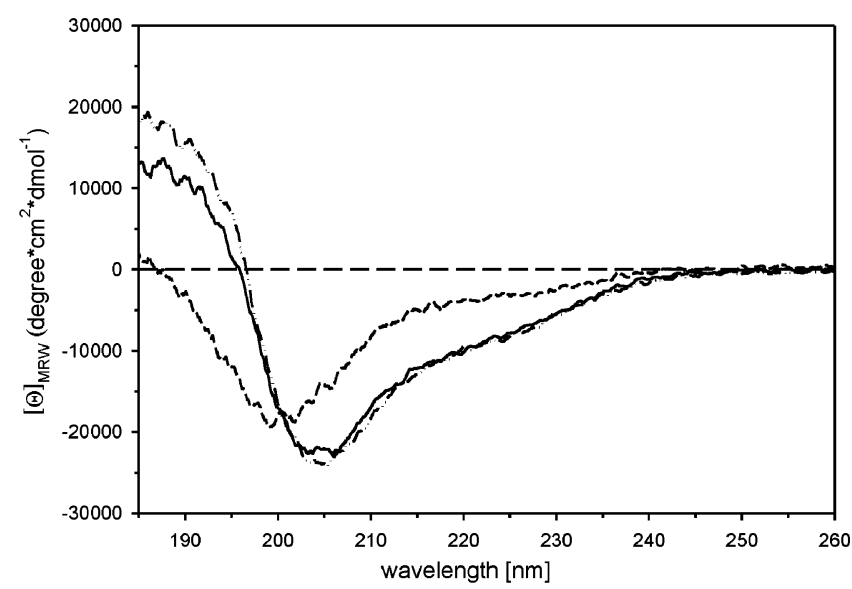

FIGURE 2: Comparison of the far-UV CD spectra of wild-type proguanylin (-・-), proguanylin-C86S/C94S (-), and proguanylinC48S/C61S ( - - ). The spectra were recorded on a Jasco J-810 spectropolarimeter at room temperature at $9.5 \mu \mathrm{M}$ wild-type proguanylin, $8.6 \mu \mathrm{M}$ proguanylin-C86S/C94S, and $6.2 \mu \mathrm{M}$ proguanylin-C48S/C61S as described in Materials and Methods.

The far-UV CD spectrum of proguanylin-C86S/C94S is typical of a protein containing $\alpha$-helix and $\beta$-sheet portions, as well as unstructured regions with a broad minimum between 205 and $230 \mathrm{~nm}$ and an intense positive band at $190 \mathrm{~nm}$ (Figure 2). The main difference between the CD spectra of wild-type proguanylin and proguanylin-C86S/ C94S is a small shift of the zero point toward shorter wavelengths for proguanylin-C86S/C94S, as well as less intense positive bands between 185 and $197 \mathrm{~nm}$, indicating an increase in unstructured portions compared to the wildtype protein (38).

For a more detailed analysis of the structural changes induced upon deletion of the Cys86-Cys94 disulfide bond, a ${ }^{15} \mathrm{~N}$ HSQC spectrum of uniformly ${ }^{15} \mathrm{~N}$-labeled proguanylinC86S/C94S was recorded (Figure 3a). Comparison of the spectrum of the wild-type protein with that of proguanylinC86S/C94S shows a reduced chemical shift dispersion of the amide proton resonances for the mutant protein, in addition to broadened signals and an enhanced signal overlap, indicating partial loss of tertiary structure, and possibly altered overall protein dynamics or partial aggregation (Figure 3a).

Despite severe spectral overlap, the following experiments performed on a sample of uniformly ${ }^{15} \mathrm{~N}$-labeled proguanylinC86S/C94S rendered sequence specific resonance assignment of 71 of the 83 amide-detected spin systems possible (Figure $3 \mathrm{a}):{ }^{15} \mathrm{~N}$ NOESY-HSQC, ${ }^{15} \mathrm{~N}$ TOCSY-HSQC, and HNHA. Additionally, for six of 11 proline residues, the $\mathrm{H} \alpha$ resonances were assigned unambiguously.

Qualitative comparison of the spectra of wild-type and mutant protein restricts differences mainly to characteristic isolated signals (Figure 3a), i.e., to the hormone region, the $\mathrm{COOH}$-terminal part of helix 3 , and the $\beta$-sheet structure connecting the termini in wild-type proguanylin (Figure $3 b$ ). Despite the drastic differences in the ${ }^{15} \mathrm{~N}$ HSQC spectra of wild-type and mutant proguanylin, the mutation has virtually no effect on residues involved in formation of the three helices and the hydrophobic core of the proguanylin structure such as Val15, Leu18, Phe53, Leu57, Leu60, and Leu73, and thus on the arrangement of the three-helix bundle (Figure $3 \mathrm{~b})$. Also, the unstructured linker region connecting helices 1 and 2 was not affected by the mutation.
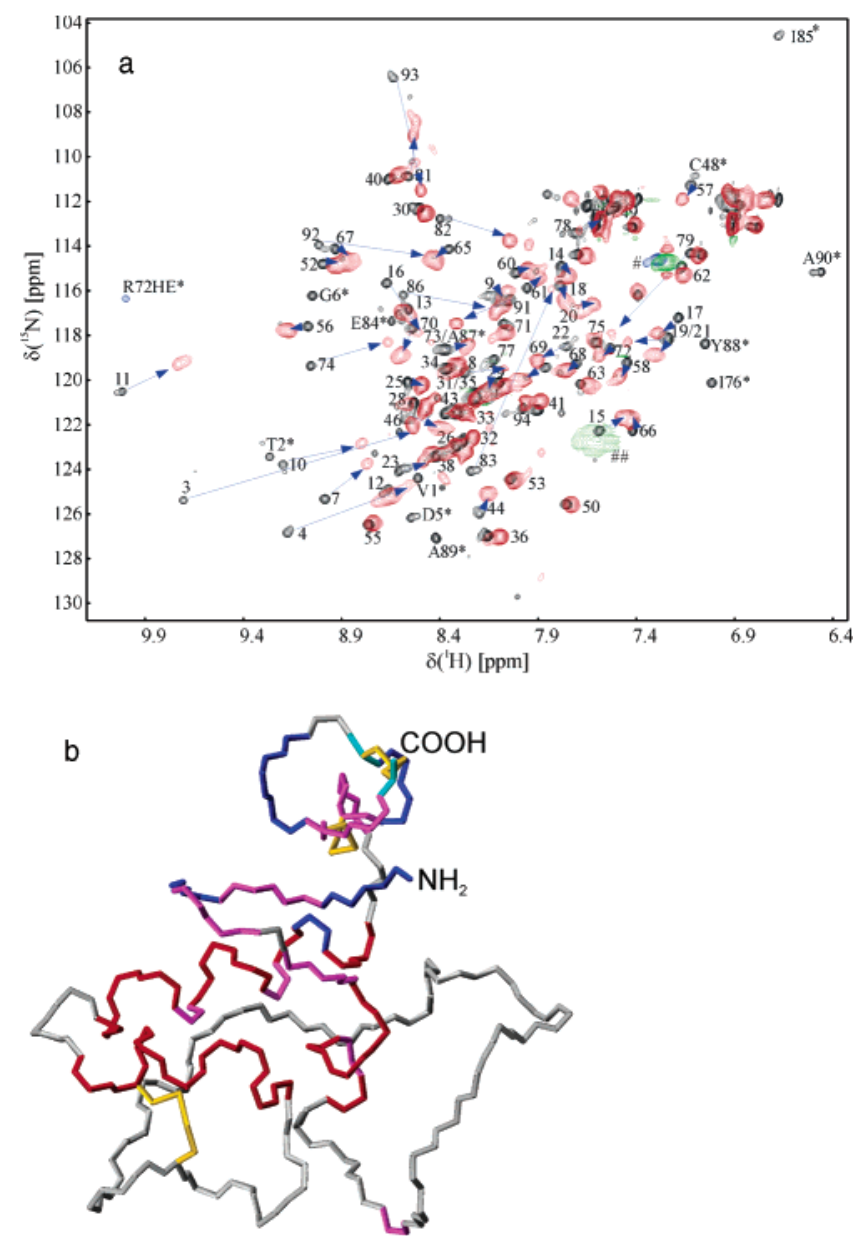

FIGURE 3: (a) Comparison of the ${ }^{15} \mathrm{~N}$ HSQC spectra of wild-type proguanylin (black and blue) and proguanylin-C86S/C94S (red and green). For wild-type proguanylin, the complete resonance assignment is indicated, and peaks of the corresponding amino acids of proguanylin-C86S/C94S are denoted with blue arrows. Residues that could not be assigned for proguanylin-C86S/C94S are labeled in the one-letter code and marked with an asterisk for wild-type proguanylin. Aliased peaks are colored blue and green, respectively. The spectra were recorded at $293 \mathrm{~K}$ and $600 \mathrm{MHz}$ (1.1 mM wildtype proguanylin) or $400 \mathrm{MHz}(1 \mathrm{mM}$ proguanylin-C86S/C94S) using the buffer conditions described in Materials and Methods. (b) Mapping of the chemical shift differences observed for the amide protons of wild-type and mutant proguanylin (taken from panel a) on the proguanylin structure ( $\mathrm{C} \alpha$ backbone trace). Helical elements are in red, chemical shift differences of $>0.15 \mathrm{ppm}\left({ }^{1} \mathrm{H}\right)$ and $>1$ ppm $\left({ }^{15} \mathrm{~N}\right)$ are in magenta. Residues in blue could not be assigned for proguanylin-C86S/C94S but gave rise to drastic changes in the HSQC spectra (a). The substituted cysteine residues are highlighted in green. Panel b was generated with MOLMOL (41).

To further analyze and quantify the differences observed in the NMR spectra (Figure 3a) with respect to changes in the secondary structure of proguanylin-C86S/C94S, we compared the $\mathrm{H} \alpha$ secondary chemical shifts of wild-type proguanylin and proguanylin-C86S/C94S using the random coil values of Wishart et al. (39) (Figure 4). For most of the sequence, this comparison shows good agreement of the secondary chemical shifts for both proteins, particularly for the three helices and the unstructured linker region (Figure 4), thus confirming the above observations of the ${ }^{15} \mathrm{~N}$ HSQC spectra (Figure 3a,b). Moreover, formation of the hydrophobic core structure and the helices is corroborated by several characteristic long-range NOE connectivities, as well as strong magnetic shielding of the methyl groups of Leu57 


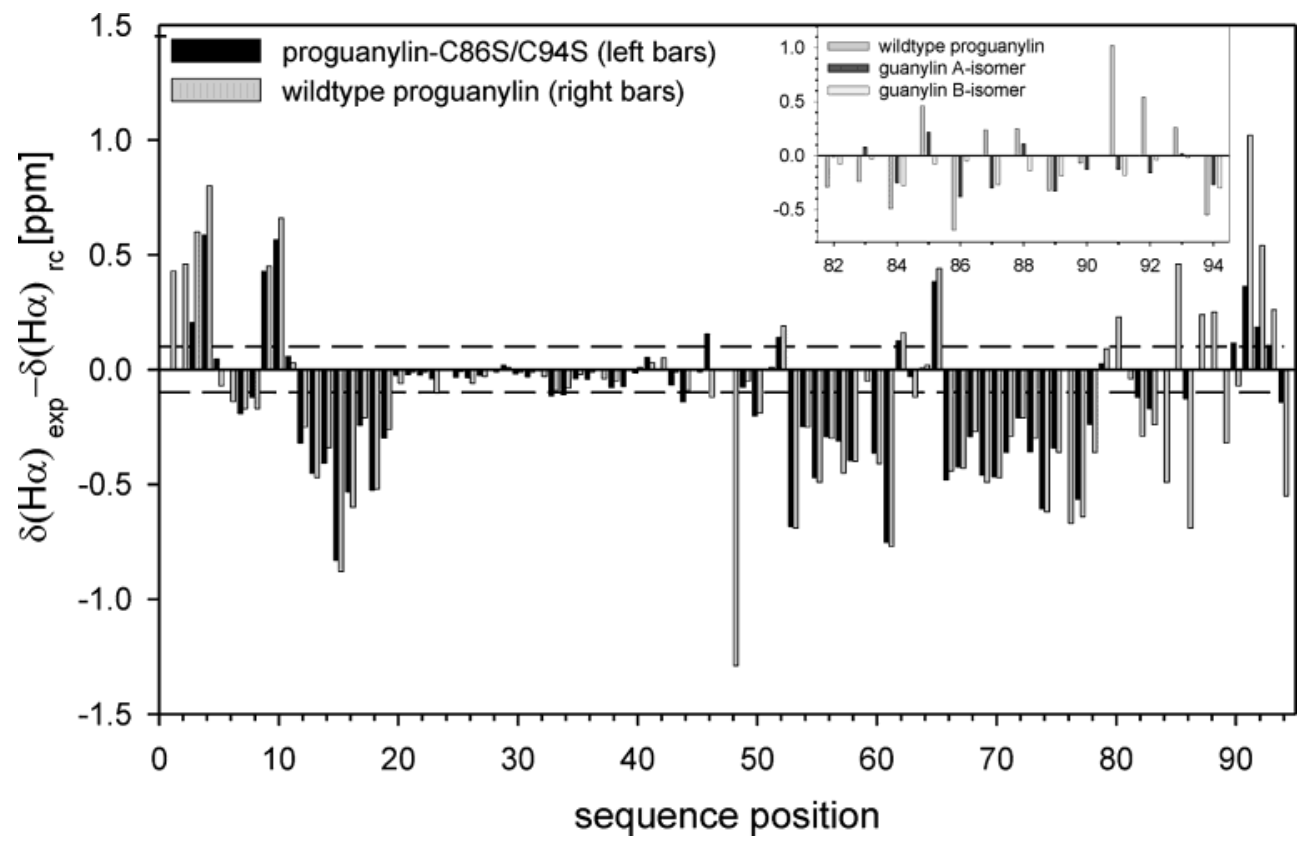

FIGURE 4: H $\alpha$ secondary chemical shifts of proguanylin-C86S/C94S (black, left bars) and wild-type proguanylin (gray, right bars). The H $\alpha$ secondary chemical shifts were calculated using the random coil values given by Wishart et al. (39). The inset shows H $\alpha$ secondary chemical shifts of wild-type proguanylin residues 82-94 (15) and of the guanylin A- and B-isomers (10).

(0.322 ppm for $\mathrm{H} \delta 1$ and $-0.02 \mathrm{ppm}$ for $\mathrm{H} \delta 2$ ) caused by interaction with the aromatic side chains of Phe53 and Phe10 as observed for wild-type proguanylin. Also, the most pronounced differences of the $\mathrm{H} \alpha$ secondary chemical shifts of wild-type and mutant proguanylin are in agreement with the observations made in the ${ }^{15} \mathrm{~N}$ HSQC spectra, as they are restricted to the first and third $\beta$-strand, resulting in significantly less-pronounced downfield shift values for residues Val3, Gln4, Cys91, Thr92, and Gly93 (Figure 4). These and the major chemical shift differences observed between the ${ }^{15} \mathrm{~N}$ HSQC spectrum of proguanylin-C86S/C94S and the ${ }^{15} \mathrm{~N}$ HSQC spectrum of the wild-type protein are most likely due to a pronounced attenuation of the tertiary interactions between the hormone region and the prosequence since the $\beta$-sheet typical long-range interactions present in the wildtype protein could not be observed in the ${ }^{15} \mathrm{~N}$ NOESY-HSQC spectrum of proguanylin-C86S/C94S.

Despite this pronounced attenuation of the tertiary contacts between $\beta 1$ and $\beta 3$, residues Val3, Gln4, Cys91, Thr92, and Gly93 maintain their preference for an extended backbone conformation as deduced from secondary chemical shift analysis (Figure 4). The chemical shifts of the hormone region of proguanylin-C86S/C94S thus remain more similar to that of wild-type proguanylin than to that of biologically active 13-amino acid guanylin [corresponding to residues $82-94$ of proguanylin $(10,15)$, inset of Figure 4], indicating residual tertiary contacts that lead to structural stabilization of the hormone region are present. In contrast, for 15-residue guanylin lacking the respective disulfide bond, the tertiary structure seems to be lost as this peptide is biologically inactive (9). Therefore, on one hand, the conformation of the hormone region of proguanylin-C86S/C94S must be induced by the prosequence and confirms the assumption of a direct effect of the prosequence on the topology of the hormone region. On the other hand, comparison of proguanylin-C86S/C94S with wild-type proguanylin reveals that only in the presence of both native disulfide bonds of the hormone region, i.e., Cys83-Cys91 and Cys86-Cys94, are numerous tertiary contacts possible for stabilization of the sheet and the hormone structure (Figure 3) (15). These results indicate a mutual influence of the prosequence and the $\mathrm{COOH}$-terminal disulfide bonds on the stability of the prohormone structure.

Spectroscopic Analysis of Proguanylin-C48S/C61S. These results therefore support the opinion that the structural requirements of the prosequence of guanylin are crucial and sufficient for correct structure and disulfide formation in the hormone region of proguanylin. This precursor protein, however, contains a third disulfide bond (Cys48-Cys61) located in the prosequence of guanylin for which no explicit function could be assigned. We therefore investigated a possible stabilizing function of this disulfide bond with respect to the overall three-dimensional structure of the guanylin precursor protein as well as its contribution to the correct formation of the remaining disulfide bonds by substitution of both cysteine residues with serine. The resulting protein proguanylin-C48S/C61S was analyzed by far-UV CD as well as NMR spectroscopy.

In comparison to the far-UV CD spectrum of wild-type proguanylin, both the zero point and the global minimum of the CD spectrum of proguanylin-C48S/C61S are significantly shifted toward shorter wavelengths and accompanied by an overall loss of signal intensity (Figure 2). The CD spectrum of proguanylin-C48S/C61S is thus typical of a protein with only a very small proportion of regular secondary structure (38).

To further examine this observation with respect to the overall three-dimensional fold of the mutant protein, a ${ }^{15} \mathrm{~N}$ HSQC spectrum of proguanylin-C48S/C61S was recorded (Figure 5), showing a dramatically reduced chemical shift dispersion compared to that of wild-type proguanylin. This loss of signal dispersion for proguanylin-C48S/C61S corresponds to a loss of the well-defined three-dimensional structure upon deletion of the Cys48-Cys61 disulfide bond and thus confirms the observations made with the far-UV 


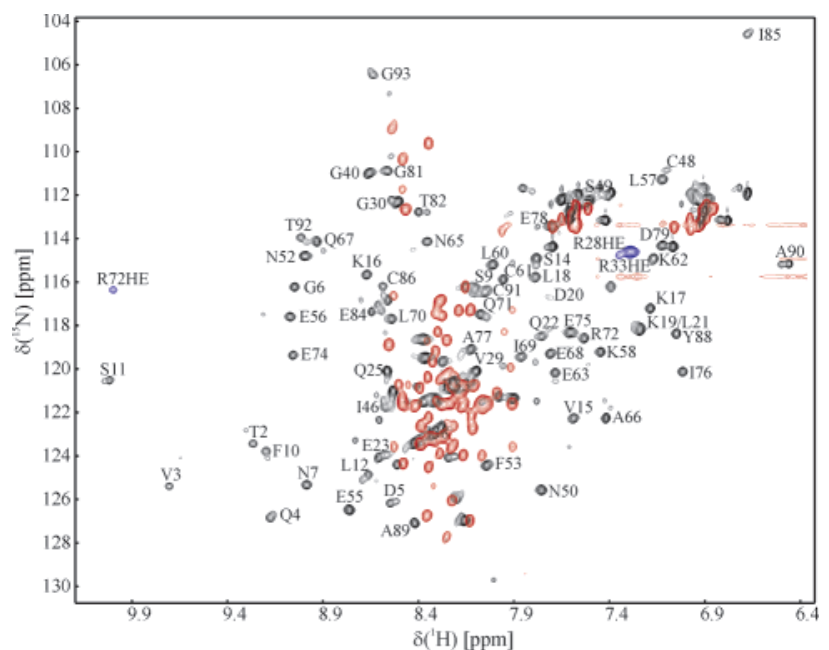

FIGURE 5: Comparison of the ${ }^{15} \mathrm{~N}$ HSQC spectra of wild-type proguanylin (black and blue) and proguanylin-C48S/C61S (red). For clarity, most of the resonance assignment of wild-type proguanylin is indicated. Aliased peaks are colored blue. The spectra were recorded at $293 \mathrm{~K}$ and $600 \mathrm{MHz}$ (1.1 mM wild-type proguanylin) or $400 \mathrm{MHz}(0.6 \mathrm{mM}$ proguanylin-C48S/C61S) using the buffer conditions described in Materials and Methods.

CD spectra (Figure 2). The Cys48-Cys61 disulfide bond is thus essential for structure stabilization of proguanylin.

Disulfide Analysis of Proguanylin-C48S/C61S. To investigate whether proguanylin-C48S/C61S is still able to form the correct disulfide bonds in the hormone region despite the severe loss of tertiary structure in this protein, disulfide analysis was carried out by analytical HPLC and mass spectrometry after the protein had been treated with acetic acid (see Materials and Methods and refs 14 and 18) (Figure 6). Biologically active guanylin with the native $1-3 / 2-4$ disulfide connectivity is able to form two interconvertable topological isomers that give rise to a characteristic double peak in the chromatogram of acetic acid-treated proguanylin (Figure 6a, double peak 1) $(14,18)$. This characteristic double peak is also found for acetic acid-treated proguanylin-C48S/ C61S (Figure 6b, double peak 1), in addition to two peaks of identical molecular masses corresponding to the inactive disulfide isomers with $1-4 / 2-3$ and $1-2 / 3-4$ connectivities (Figure 6b, peaks 2 and 3, respectively), as deduced from comparison with reoxidized synthetic guanylin peptides (14). Relative amounts of the different disulfide species are 22 , 66 , and $12 \%$ for the $1-3 / 2-4$ (native, active), $1-4 / 2-3$ (non-native, inactive), and 1-2/3-4 (non-native, inactive) connectivities, respectively. This amount of native disulfides is $\sim 3$-fold higher than that obtained from oxidative folding of reduced 15-amino acid guanylin (i.e., proguanylin residues 80-94) that almost completely results in the formation of the two inactive disulfide isomers with only $5-10 \%$ of native disulfides (14). The relative amount of native disulfide connectivity of $22 \%$ obtained for the remaining disulfides of proguanylin-C48S/C61S is thus most likely due to a small proportion of correctly folded proguanylin-C48S/C61S that enables correct disulfide formation.

Disulfide-Coupled Folding of Proguanylin. On the basis of the experiments described so far, the function of the Cys48-Cys61 disulfide bond is likely to be the stabilization of the three-dimensional structure of the guanylin prohormone. Involvement of one or both of the cysteine residues of the prosequence (i.e., Cys48 or Cys61) in disulfide shuffling during oxidative folding of proguanylin, however, could not be completely excluded. We therefore performed oxidative refolding kinetics on wild-type proguanylin for a period of $10 \mathrm{~min}$ to $18 \mathrm{~h}$. After the folding reaction had been quenched by acidification at different times after the initiation of refolding, samples were treated with acetic acid to release the hormone region and analyzed by gel electrophoresis (Figure 7). Acetic acid cleavage of reoxidized wild-type proguanylin produced distinct bands with molecular masses of approximately 2, 6, and $9 \mathrm{kDa}$ (Figure 7, marked with arrows), corresponding to proguanylin fragments -2 to 20 (2395 Da), 6-20 (1699 Da), 80-94 (1458 Da), 21-79 (6672

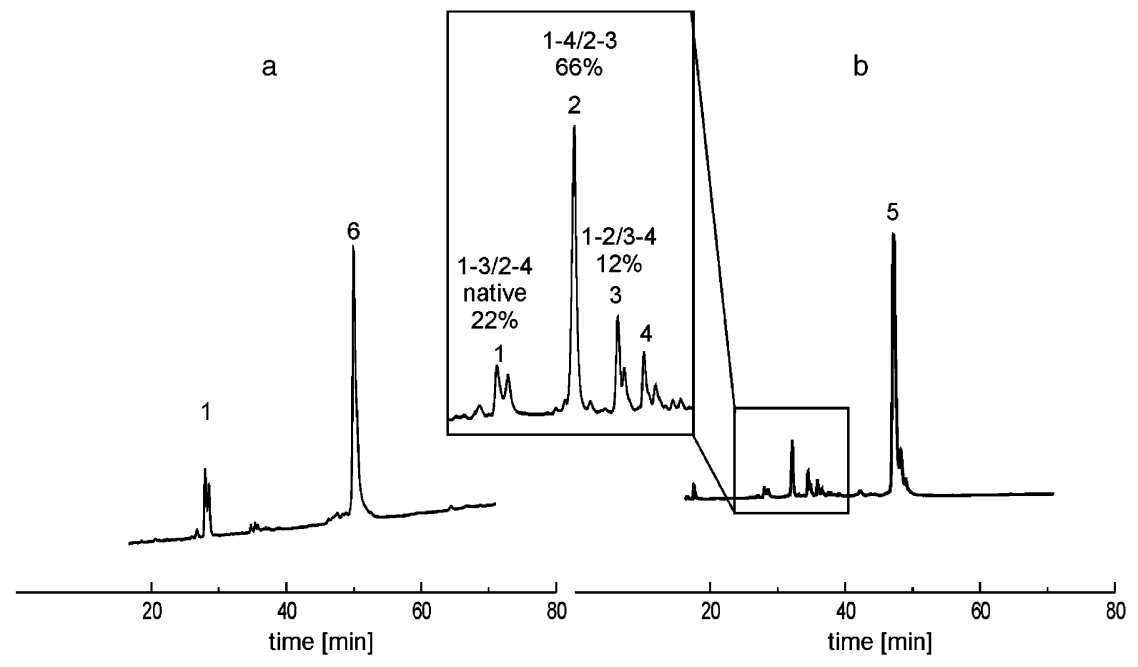

FIGURE 6: HPLC analysis of acetic acid cleavage of wild-type proguanylin (a) and proguanylin-C48S/C61S (b). Cleavage occurred at the labile Asp79-Pro80 peptide bond, as well as after Asp5 and Asp20. Peak 1 is a double peak corresponding to the rapidly interconverting topological isomers of guanylin (proguanylin residues 80-94) with $1-3 / 2-4$ disulfide connectivity (native, active), peak 2 guanylin with $1-4 / 2-3$ connectivity (non-native, inactive), and peak 3 guanylin with $1-2 / 3-4$ connectivity (non-native, inactive). Peaks $1-3$ arise from different disulfide connectivities and correspond to molecular masses of $1458 \mathrm{Da}$ each. Peak 4 is proguanylin residues -2 to 20 (GPVTVQDGNFSFSLESVKKLKD, molecular mass of $2395 \mathrm{Da}$ ), peak 5 the prosequence of proguanylin-C48S/C61S, i.e., residues -2 to 79 (molecular mass of $9020 \mathrm{Da}$ ) as well as residues 6-79 (molecular mass of $8323 \mathrm{Da}$ ), and peak 6 the prosequence of recombinant wild-type proguanylin (molecular mass of $9050 \mathrm{Da}$ ). 


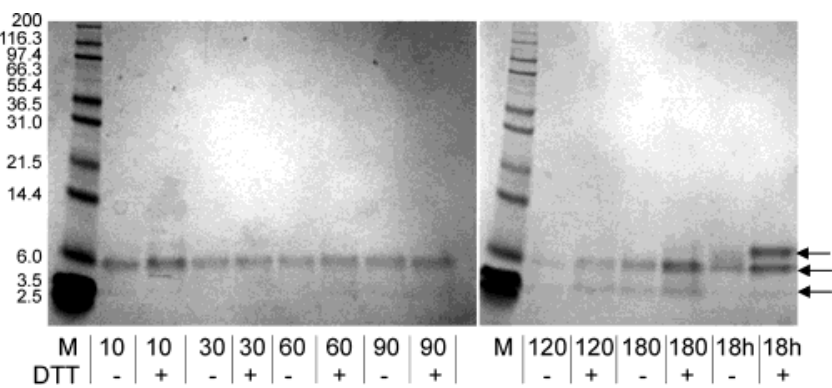

FIgURE 7: Reoxidation of reduced wild-type proguanylin. The folding reaction was quenched after $10,30,60,90,120$, and 180 min and $18 \mathrm{~h}$ by acidification, and samples were subjected to acetic acid cleavage. Cleavage products are analyzed in the presence and absence of $10 \mathrm{mM}$ DTT as indicated.

$\mathrm{Da})$, and -2 to $79(9050 \mathrm{Da})$. These fragments result from cleavage after Asp5, Asp20, and Asp79 as also observed with proguanylin-C48S/C61S (Figure 6). Importantly, at all times the fragment pattern is independent of the presence of a reducing agent (Figure 7), thus ruling out disulfide bonds between cysteine 48 or 61 and the hormone region (i.e., cysteine $83,86,91$, or 94) which would have led to the observed molecular masses (Figure 7) only in the presence of a reducing agent and to masses of $8130 \mathrm{Da}(21-79+$ 80-94), $9829 \mathrm{Da}(6-79+80-94)$, or $10509 \mathrm{Da}(-2$ to $79+80-94)$ in the absence of such an agent. Therefore, disulfide formation exclusively depends on the correct threedimensional structure of proguanylin, as expected from the results obtained from spectroscopic analysis of proguanylin$\mathrm{C} 86 \mathrm{~S} / \mathrm{C} 94 \mathrm{~S}$ as well as from the spectroscopic and disulfide analysis of proguanylin-C48S/C61S. The crucial role of the Cys48-Cys61 disulfide bond during disulfide-coupled folding is therefore not the formation of intramolecular disulfide intermediates but rather the stabilization of the hydrophobic core, and the relative amount of native disulfide connectivity of $22 \%$ obtained for the remaining disulfides of proguanylin$\mathrm{C} 48 \mathrm{~S} / \mathrm{C} 61 \mathrm{~S}$ is therefore indeed due to a small proportion of correctly folded protein.

Consistent with these results, disulfide bonds between the prosequence and the hormone region have also never been identified for different $\mathrm{NH}_{2}$-terminally truncated variants of both proguanylin and prouroguanylin that all exhibited nonnative disulfide connectivities in the hormone region (17) but a correctly formed disulfide bond in the prosequence (14).

The Guanylin Prosequence Directly Affects the Structure of the Hormone Region. All data available concerning the structure and folding of proguanylin imply that the interactions between the termini of proguanylin function to cause formation of the native disulfide bonds of guanylin and stabilize the bioactive conformation of this peptide hormone during the folding of the prohormone. The essential structure of the prosequence is in turn stabilized by the first disulfide bond. Hence, two different processes are likely to contribute to formation of the native disulfide connectivities of the hormone region in a cooperative manner. First, the structure of the prosequence provides a scaffold for the orientation of the $\mathrm{NH}_{2}$-terminal residues to interact with the $\mathrm{COOH}$ terminal hormone region via a small triple-stranded $\beta$-sheet. As deduced from structural analysis of proguanylin-C86S/ C94S, this interaction has a direct effect on the hormone topology and thereby favors formation of the native disulfide bonds. Second, the native disulfide bonds exhibit a stabilizing effect on the tertiary structure of the prohormone and thus trap the native structure and disulfides. This is in agreement with the observation that nonrandom conformations on the folding pathway of a protein will favor formation of a specific disulfide bond and, vice versa, a specific disulfide bond will favor and stabilize a specific conformation (40).

\section{ACKNOWLEDGMENT}

We thank Nadine Herz for excellent technical support.

\section{REFERENCES}

1. Currie, M. G., Fok, K. F., Kato, J., Moore, R. J., Hamra, F. K., Duffin, K. L., and Smith, C. E. (1992) Guanylin: an endogenous activator of intestinal guanylate cyclase, Proc. Natl. Acad. Sci. U.S.A. 89, 947-951.

2. Forte, L. R., Freeman, R. H., Krause, W. J., and London, R. M. (1999) Guanylin peptides: cyclic GMP signaling mechanisms, Braz. J. Med. Biol. Res. 32, 1329-1336.

3. Forte, L. R., London, R. M., Freeman, R. H., and Krause, W. J. (2000) Guanylin peptides: renal actions mediated by cyclic GMP, Am. J. Physiol. 278, F180-F191.

4. Forte, L. R. (2003) A novel role for uroguanylin in the regulation of sodium balance, J. Clin. Invest. 112, 1138-1141.

5. Lorenz, J. N., Nieman, M., Sabo, J., Sanford, L. P., Hawkins, J. A., Elitsur, N., Gawenis, L. R., Clarke, L. L., and Cohen, M. B. (2003) Uroguanylin knockout mice have increased blood pressure and impaired natriuretic response to enteral $\mathrm{NaCl}$ load, J. Clin. Invest. 112, 1244-1254.

6. Carrithers, S. L., Ott, C. E., Hill, M. J., Johnson, B. R., Cai, W., Chang, J. J., Shah, R. G., Sun, Y., Mann, E. A., Fonteles, M. C., Forte, L. R., Jackson, B. A., Giannella, R. A., and Greenberg, R. N. (2004) Guanylin and uroguanylin induce natriuresis in mice lacking guanylyl cyclase-C receptor, Kidney Int. 65, 40-53.

7. Forte, L. R. (1999) Guanylin regulatory peptides: structures, biological activities mediated by cyclic GMP and pathobiology, Regul. Pept. 81, 25-39.

8. Vaandrager, A. B. (2002) Structure and function of the heat-stable enterotoxin receptor/guanylyl cyclase C, Mol. Cell. Biochem. 230, 73-83.

9. Klodt, J., Kuhn, M., Marx, U. C., Martin, S., Rösch, P., Forssmann, W. G., and Adermann, K. (1997) Synthesis, biological activity and isomerism of guanylate cyclase $\mathrm{C}$-activating peptides guanylin and uroguanylin, J. Pept. Res. 50, 222-230.

10. Skelton, N. J., Garcia, K. C., Goeddel, D. V., Quan, C., and Burnier, J. P. (1994) Determination of the solution structure of the peptide hormone guanylin: observation of a novel form of topological stereoisomerism, Biochemistry 33, 13581-13592.

11. Schulz, A., Escher, S., Marx, U. C., Meyer, M., Rösch, P. Forssmann, W. G., and Adermann, K. (1998) Carboxy-terminal extension stabilizes the topological stereoisomers of guanylin, $J$. Pept. Res. 52, 518-525.

12. Kuhn, M., Raida, M., Adermann, K., Schulz-Knappe, P., Gerzer, R., Heim, J. M., and Forssmann, W. G. (1993) The circulating bioactive form of human guanylin is a high molecular weight peptide (10.3 kDa), FEBS Lett. 318, 205-209.

13. Garcia, K. C., de Sauvage, F. J., Struble, M., Henzel, W., Reilly, D., and Goeddel, D. V. (1993) Processing and characterization of human proguanylin expressed in Escherichia coli, J. Biol. Chem. 268, 22397-22401.

14. Schulz, A., Marx, U. C., Hidaka, Y., Shimonishi, Y., Rösch, P., Forssmann, W. G., and Adermann, K. (1999) Role of the prosequence of guanylin, Protein Sci. 8, 1850-1859.

15. Lauber, T., Neudecker, P., Rösch, P., and Marx, U. C. (2003) Solution structure of human proguanylin: The role of a hormone prosequence, J. Biol. Chem. 278, 24118-24124.

16. Hidaka, Y., Ohno, M., Hemmasi, B., Hill, O., Forssmann, W. G., and Shimonishi, Y. (1998) In vitro disulfide-coupled folding of guanylyl cyclase-activating peptide and its precursor protein, Biochemistry 37, 8498-8507.

17. Hidaka, Y., Shimono, C., Ohno, M., Okumura, N., Adermann, K., Forssmann, W. G., and Shimonishi, Y. (2000) Dual function of the propeptide of prouroguanylin in the folding of the mature peptide: disulfide-coupled folding and dimerization, J. Biol. Chem. $275,25155-25162$. 
18. Lauber, T., Nourse, A., Schulz, A., and Marx, U. C. (2002) Native and recombinant proguanylin feature identical biophysical properties and are monomeric in solution, Biochemistry 41, 14602-14612.

19. Ho, S. N., Hunt, H. D., Horton, R. M., Pullen, J. K., and Pease, L. R. (1989) Site-directed mutagenesis by overlap extension using the polymerase chain reaction, Gene 77, 51-59.

20. Mori, S., Abeygunawardana, C., Johnson, M. O., and Vanzij1, P. C. M. (1995) Improved sensitivity of HSQC spectra of exchanging protons at short interscan delays using a new fast HSQC (FHSQC) detection scheme that avoids water saturation, J. Magn. Reson., Ser. B 108, 94-98.

21. Vuister, G. W., and Bax, A. (1993) Quantitative J correlation: a new approach for measuring homonuclear three-bound $\mathrm{J}\left(\mathrm{H}^{\mathrm{N}}-\mathrm{H}^{\alpha}\right)$ coupling constants in ${ }^{15} \mathrm{~N}$-enriched proteins, J. Am. Chem. Soc. $115,7772-7777$

22. Zhang, W., Smithgall, T., and Gmeiner, W. H. (1997) Threedimensional structure of the Hck $\mathrm{SH} 2$ domain in solution, $J$. Biomol. NMR 10, 263-272.

23. Zhang, O., Kay, L. E., Olivier, J. P., and Forman-Kay, J. D. (1990) Backbone ${ }^{1} \mathrm{H}$ and ${ }^{15} \mathrm{~N}$ resonance assignments of the $\mathrm{N}$-terminal SH3 domain of drk in folded and unfolded states using enhancedsensitivity pulsed field gradient NMR techniques, J. Biomol. NMR $4,845-858$.

24. Talluri, S., and Wagner, G. (1996) An optimized 3D NOESYHSQC, J. Magn. Reson., Ser. B 112, 200-205.

25. Sklenar, V., Piotto, M., Leppik, R., and Saudek, V. (1993) Gradient-tailored water suppression for ${ }^{1} \mathrm{H}_{-}{ }^{15} \mathrm{~N}$ HSQC experiments optimized to retain full sensitivity, J. Magn. Reson., Ser. A 102, $241-245$.

26. Grzesiek, S., and Bax, A. (1993) The importance of not saturating $\mathrm{H}_{2} \mathrm{O}$ in protein NMR. Application to sensitivity enhancement and NOE measurements, J. Am. Chem. Soc. 115, 12593-12594.

27. Schleucher, J., Schwendinger, M. G., Sattler, M., Schmidt, P., Schedletzky, O., Glaser, S. J., Sørensen, O. W., and Griesinger, C. (1994) A general enhancement scheme in heteronuclear multidimensional NMR employing pulsed field gradients, J. Biomol. NMR 4, 301-306.

28. States, D. J., Haberkorn, R. A., and Ruben, D. J. (1982) A twodimensional nuclear Overhauser experiment with pure absorption phase in four quadrants, J. Magn. Reson. 48, 286-292.

29. Marion, D., Ikura, M., Tschudin, R., and Bax, A. (1989) Rapid recording of 2D NMR spectra without phase cycling. Applications to the study of hydrogen exchange in proteins, J. Magn. Reson. $85,393-399$.
30. Kay, L. E., Keifer, P., and Saarinen, T. (1992) Pure absorption gradient enhanced heteronuclear single quantum correlation spectroscopy with improved sensitivity, J. Am. Chem. Soc. 114, 10663-10665.

31. Sattler, M., Schwendinger, M. G., Schleucher, J., and Griesinger, C. (1995) Novel strategies for the sensitivity enhancement in heteronuclear multidimensional NMR experiments employing pulsed field gradients, J. Biomol. NMR 5, 11-22.

32. Cavanagh, J., and Rance, M. (1992) Suppression of cross-relaxation effects in TOCSY spectra via a modified DIPSI-2 mixing sequence, J. Magn. Reson. 96, 670-678.

33. Shaka, A., Barker, P. B., and Freeman, R. (1985) Computeroptimized decoupling scheme for wideband applications and lowlevel operation, J. Magn. Reson. 64, 547-552.

34. Friedrich, M. S. (1995) A Model-free algorithm for the removal of baseline artifacts, J. Biomol. NMR 5, 147-153.

35. Schweimer, K. (2000) Mehrdimensionale heteronukleare NMR Spektroskopie zur Bestimmung der Strukturen des Birkenpollenallergens Bet v 1, des Guillardia theta Rubredoxins und des [2Fe-2S] Ferredoxins aus Haliobacterium salinarum, Ph.D. Thesis, Universität Bayreuth, Bayreuth, Germany.

36. Johnson, B. A., and Blevins, R. A. (1994) NMRView: A computer program for the visualization and analysis of NMR data, J. Biomol. NMR 4, 603-614.

37. Markley, J. L., Bax, A., Arata, Y., Hilbers, C. W., Kaptein, R., Sykes, B. D., Wright, P. E., and Wüthrich, K. (1998) Recommendations for the presentation of NMR structures of proteins and nucleic acids, Pure Appl. Chem. 70, 117-142.

38. Greenfield, N., and Fasman, G. D. (1969) Computed circular dichroism spectra for the evaluation of protein conformation, Biochemistry 8, 4108-4116.

39. Wishart, D. S., Bigam, C. G., Holm, A., Hodges, R. S., and Sykes, B. D. (1995) ${ }^{1} \mathrm{H},{ }^{13} \mathrm{C}$ and ${ }^{15} \mathrm{~N}$ random coil NMR chemical shifts of the common amino acids. I. Investigations of nearest-neighbor effects, J. Biomol. NMR 5, 67-81.

40. Creighton, T. E. (2001) in Mechanisms of protein folding (Pain, R. H., Ed.) pp 250-273, Oxford University Press, New York.

41. Koradi, R., Billeter, M., and Wüthrich, K. (1996) MOLMOL: a program for display and analysis of macromolecular structures, J. Mol. Graphics 14, 51-55.

BI049667E 